\title{
Electrochemistry Enabled Selective Vicinal Fluorosulfenylation and Fluorosulfoxidation of
}

\author{
Alkenes \\ Yi Yu ${ }^{1}$, Yi-Min Jiang ${ }^{1}$, Shao-Fen $\mathrm{Wu}^{1}$, Zhaojiang Shi ${ }^{1}$, Jin-Nan $\mathrm{Wu}^{1}$, Yaofeng Yuan*1 and Ke-Yin Ye*1,2 \\ ${ }^{1}$ Key Laboratory of Molecule Synthesis and Function Discovery (Fujian Province University), College of \\ Chemistry, Fuzhou University, Fuzhou 350108 \\ ${ }^{2}$ State Key Laboratory of Physical Chemistry of Solid Surfaces, Xiamen University, Xiamen 361005 \\ *Corresponding Author(s): yaofeng_yuan@fzu.edu.cn (Y. Yuan) and kyye@fzu.edu.cn (K.-Y. Ye)
}

\begin{abstract}
Both sulfur and fluorine play important roles in organic synthesis, the life science, and materials science. The direct incorporation of these elements into organic scaffolds with precise control of the oxidation states of sulfur moieties is of great significance. Herein, we report the highly selective electrochemical vicinal fluorosulfenylation and fluorosulfoxidation reactions of alkenes, which were enabled by the unique ability of electrochemistry to dial in the potentials on demand. Preliminary mechanistic investigations revealed that the fluorosulfenylation reaction proceeded through a radical-polar crossover mechanism involving a key episulfonium ion intermediate. Subsequent electrochemical oxidation of fluorosulfides to fluorosulfoxides were readily achieved under a higher applied potential with the adventitious $\mathrm{H}_{2} \mathrm{O}$ in the reaction mixture.
\end{abstract}

\section{Keywords}

alkene $\bullet$ chemoselectivity $\bullet$ electrochemistry $\bullet$ fluorine $\bullet$ sulfur

\section{Introduction}

Alkenes are among the most prevalent and valuable feedstocks in organic synthesis. Direct and selective difunctionalization of alkenes, which simultaneously adds two synthetically valuable functionalities across a double bond, is a straightforward and economical approach to construct functionalized targets with high 
molecular complexities. ${ }^{1-3}$ Specifically, the direct incorporation of sulfur ${ }^{4,5}$ and fluorine ${ }^{6}$ into alkenes has attracted intensive research interest of synthetic chemists due to the important roles of both elements in organic synthesis, life science, and materials science. For instance, organic molecules containing both sulfur and fluorine are present in many well-received pharmaceuticals, such as Flovent, Faslodex, and Glecaprevir (Scheme 1A). Additionally, the spatial vicinity of these two elements further renders these types of compounds as ideal research targets of the fundamentally intriguing sulfur-fluorine gauche effect. ${ }^{7}$ It was found that the oxidation states of sulfur in these compounds are strongly correlated with their functions. Therefore, it is highly desirable to develop synthesis protocols to simultaneously introduce sulfur and fluorine elements into targeted molecules with precise control of the oxidation states of the sulfur moieties. ${ }^{8-10}$

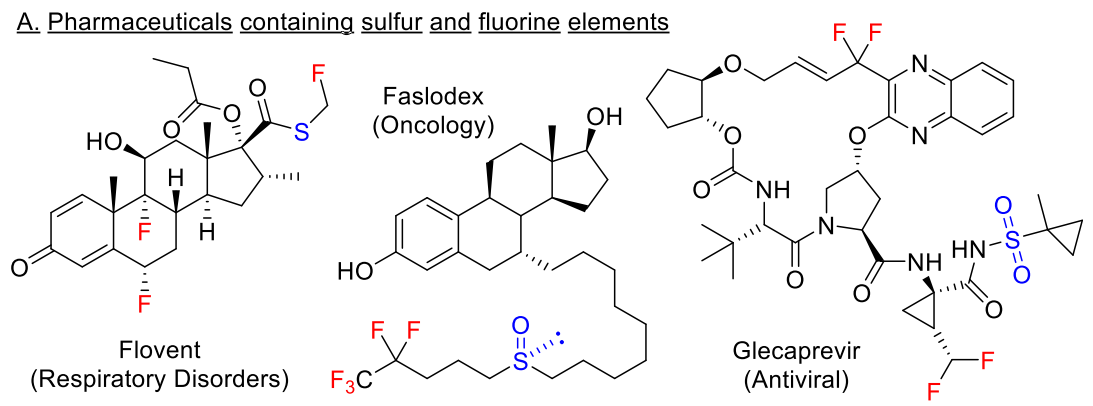

B. Fluorosulfenylation of alkenes (previous work)

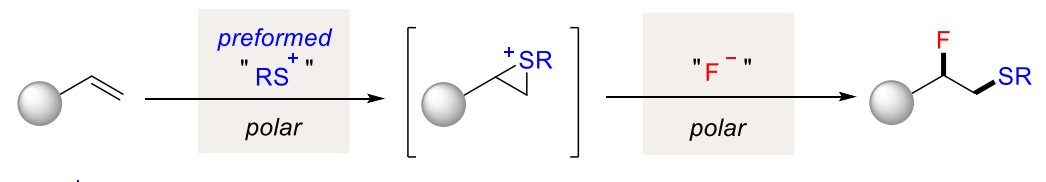

$" \mathrm{RS}^{+} "=\mathrm{PhSCl}, \mathrm{PhSNHAr}\left(\mathrm{BF}_{3}\right), \operatorname{ArS}-\mathrm{NR}_{2}, \mathrm{RS}(\mathrm{RSSR})^{+} \mathrm{BF}_{4}{ }^{-}$

C. Fluorosulfonvlation of alkenes (previous work)

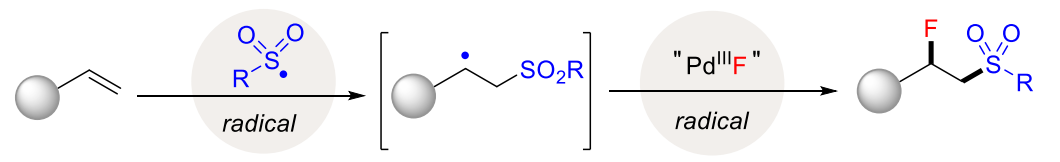

D. Electrochemical fluorosulfenylation and fluorosulfoxidation of alkenes (this work)

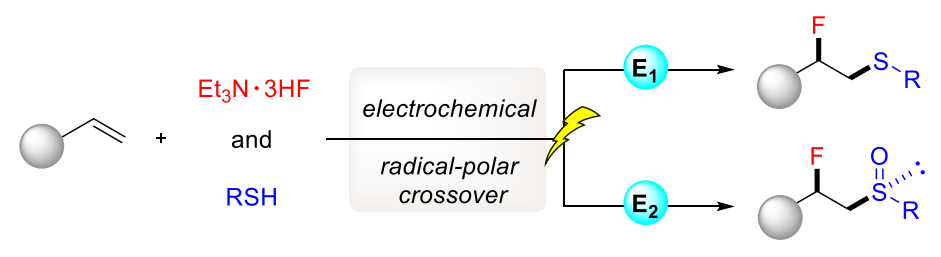

Scheme 1 | Direct Incorporation of Sulfur and Fluorine Elements into Alkenes 
Typically, the vicinal fluorosulfenylation of alkenes is achieved by the reaction of alkenes with a chemically ${ }^{11-17}$ or electrochemically ${ }^{18}$ generated electrophilic thiolating agent ("RS ${ }^{+ \text {") }}$ to form an episulfonium ion $^{19}$ followed by nucleophilic fluorination (Scheme 1B). Such a polar approach, however, is limited by the requisite preparation of highly reactive and toxic thiolating agents. Notably, Liu and co-workers ${ }^{20}$ developed an elegant radical strategy for the intermolecular fluorosulfonylation of styrenes via a high-valence palladium species. ${ }^{21-22}$ However, a superstoichiometric strong oxidizing agent (NFSI) was required (Scheme 1C). In contrast, the analogously direct fluorosulfoxidation of alkenes has not been reported yet due to the difficulty in accessing the electrophilic or radical sulfoxide species. ${ }^{23}$

Green and sustainable electrosynthesis ${ }^{24-29}$ could provide innovative solutions to address the challenges associated with conventional organic synthesis. To this end, one of the most prominent features of electrochemistry in organic synthesis is its unique capability to control reactivity via "dialed-in" specific potential when necessary. By contrast, chemical agents only bear their innately fixed redox potentials and thus extensively screening of various chemical oxidants or reductants are generally required in a typical redox reaction. Therefore, electrosynthesis is capable to regulate reactions within a much wider redox window. ${ }^{30,31} \mathrm{In}$ addition, the precise control of a minimally sufficient potential also allows better functional compatibility. ${ }^{32}$ In particular, electrochemical methods have been demonstrated to be capable of incorporating either sulfur ${ }^{33,34}$ or fluorine ${ }^{35-38}$ functionalities into diverse organic frameworks. Inspired by the elegant sulfonyl fluoride $\left(\mathrm{RSO}_{2}-\right.$ F) synthesis via the electrochemical oxidative coupling of thiols (RSH) and potassium fluoride (KF) reported by Noël and co-workers, ${ }^{39,40}$ we speculated that electrochemistry should be an ideal solution to simultaneously ${ }^{41}$ introduce both fluorine and sulfur in a controllable oxidation state into alkenes. Herein, we report an electrochemical radical-polar crossover approach for the highly selective fluorosulfenylation and fluorosulfoxidation of alkenes in which the selectivity was well controlled by the judicious choice of the applied potential (Scheme 1D).

\section{Experimental Methods}


General procedure for the electrochemical vicinal fluorosulfenylation of alkenes (constant cell-potential electrolysis): In an oven-dried undivided three-necked glassware $(25 \mathrm{~mL})$ equipped with a stirring bar, thiophenol substrate $(0.3 \mathrm{mmol})$ were added. The glassware was equipped with carbon cloth $(15 \mathrm{~mm} \times 15 \mathrm{~mm}$ $\times 0.1 \mathrm{~mm})$ as the anode and platinum plate $(15 \mathrm{~mm} \times 15 \mathrm{~mm} \times 0.3 \mathrm{~mm})$ as the cathode. Under the protection of $\mathrm{N}_{2}$, olefin substrate (1.5 equiv.), $\mathrm{Et}_{3} \mathrm{~N} \cdot 3 \mathrm{HF}(0.5 \mathrm{~mL})$, and $\mathrm{CH}_{3} \mathrm{CN}(10 \mathrm{~mL})$ were injected respectively into the glassware via syringes. The reaction mixture was stirred and electrolyzed at a constant cell potential of $1.8 \mathrm{~V}$ at $40{ }^{\circ} \mathrm{C}$ for $6 \mathrm{~h}$. The reaction mixture was subsequently poured into a saturated sodium bicarbonate solution (ca. $15 \mathrm{~mL})$. The aqueous layer was separated and extracted with dichloromethane $(3 \times 5 \mathrm{~mL})$, and the combined organic layers were washed with brine and dried over sodium sulfate. Following concentration in vacuo, the crude residue was subjected to flash column chromatography on silica gel to yield the desired product.

General procedure for the electrochemical vicinal fluorosulfoxidation of alkenes: In an oven-dried undivided three-necked glassware $(25 \mathrm{~mL})$ equipped with a stir bar, thiophenol substrate $(0.3 \mathrm{mmol})$ were added. The glassware was equipped with carbon cloth $(15 \mathrm{~mm} \times 15 \mathrm{~mm} \times 0.1 \mathrm{~mm})$ as the anode and platinum plate $(15$ $\mathrm{mm} \times 15 \mathrm{~mm} \times 0.3 \mathrm{~mm})$ as the cathode. Under the protection of $\mathrm{N}_{2}$, olefin substrate $(1.7$ equiv. $), \mathrm{Et}_{3} \mathrm{~N} \cdot 3 \mathrm{HF}(1$ $\mathrm{mL}), \mathrm{CH}_{3} \mathrm{COOH}$ (3 equiv.), $\mathrm{CCl}_{4}$ (1.0 equiv.) and $\mathrm{CH}_{3} \mathrm{CN}(10 \mathrm{~mL})$ were injected respectively into the glassware via syringes. The reaction mixture was stirred and the electrolysis was initiated at a constant cell

potential of $2.8 \mathrm{~V}$ at $40{ }^{\circ} \mathrm{C}$. The electrical input was removed after $4 \mathrm{~h}$. The reaction mixture was subsequently poured into a saturated sodium bicarbonate solution (ca. $15 \mathrm{~mL}$ ). The aqueous layer was separated and extracted with dichloromethane $(3 \times 5 \mathrm{~mL})$, and the combined organic layers were washed with brine and dried over sodium sulfate. Following concentration in vacuo, the crude residue was subjected to flash column chromatography on silica gel to yield the desired product. More details and characterization of products are available in Supporting Information.

\section{Results and Discussion}

\section{Reaction optimizations}


We commenced our investigations on the direct vicinal fluorosulfenylation by choosing styrene (1), 4chlorothiophenol (2), and triethylamine trihydrofluoride $\left(\mathrm{Et}_{3} \mathrm{~N} \cdot 3 \mathrm{HF}\right)$ as the model substrates. With a carbon cloth anode and a Pt cathode in an undivided cell, constant-cell-potential electrolysis $\left(\mathrm{E}_{\text {cell }}=1.8 \mathrm{~V}\right)$ in $\mathrm{MeCN}$ at $40{ }^{\circ} \mathrm{C}$ delivered the desired fluorosulfide (3) in an optimal 77\% isolated yield (Table 1, entries 1-3). No overoxidation of the sulfide product was observed under these conditions. Notably, $\mathrm{Et}_{3} \mathrm{~N} \cdot 3 \mathrm{HF}$ in this reaction served not only as the fluorinating agent but also as the electrolyte owing to its ionic nature. ${ }^{42}$ The isolated yield of fluorosulfide was depressed along with decrease of the loading of $\mathrm{Et}_{3} \mathrm{~N} \cdot 3 \mathrm{HF}$. Other fluorinating agents such as Olah's reagent (Py•9HF), however, did not promote this transformation, and the formation of aryl disulfide was observed instead. A proof-of-concept experiment with the synthesis of fluorosulfoxide (4) by increasing the applied cell potential $(2.5 \mathrm{~V})$ was conducted (entry 4). Interestingly, the employment of $\mathrm{CCl}_{4}(1$ equiv.) as the additive was found to be pivotal for the formation of fluorosulfoxide. ${ }^{43,44}$ The higher applied cell potential $(2.8 \mathrm{~V})$ and the higher loading of styrene $(1.7$ equiv. $)$ and $\mathrm{Et}_{3} \mathrm{~N} \cdot 3 \mathrm{HF}(1 \mathrm{~mL})$ were found to be beneficial (entries 5 and 6). Ultimately, the optimal yield of fluorosulfoxide (4,66\%) was achieved under constant-current electrolysis (CCE) conditions (CCE at $20 \mathrm{~mA}$ for $4 \mathrm{~h}$, entry 7). Note that the oxidation of fluorosulfide (3) to fluorosulfoxide (4) with a terminal chemical oxidant such as $m$-CPBA led to a low yield (47\%) accompanied by the overoxidized fluorosulfone (Supporting Information).

Table 1. Optimization of Reaction Conditions ${ }^{a}$ 


\begin{tabular}{lccccc}
1 & & & & \\
\hline
\end{tabular}

${ }^{a}$ Reaction conditions: undivided cell, carbon cloth anode, Pt cathode, $1(0.45 \mathrm{mmol}), 2(0.3 \mathrm{mmol}), \mathrm{Et} 3 \mathrm{~N} \cdot 3 \mathrm{HF}(0.5 \mathrm{or} 1 \mathrm{~mL})$, $\mathrm{MeCN}(10 \mathrm{~mL})$ at $40{ }^{\circ} \mathrm{C}$; yield was determined by ${ }^{19} \mathrm{~F}$ NMR with (trifluoromethoxy)benzene as the internal standard; ${ }^{b}$ isolated yield; ${ }^{c} 1$ equiv. of $\mathrm{CCl}_{4}$ as the additive; ${ }^{d} 0.51 \mathrm{mmol}$ of $\mathbf{1}$ used.

\section{Substrate scope}

With the optimal reaction conditions determined, we first evaluated the scope of the electrochemical fluorosulfenylation of alkenes (Table 2). This reaction accommodated a wide array of para-, meta-, and orthosubstituted styrenes (5-17). Additionally, alkyl (18-21), benzyl (22), pyridyl (23), and cycloalkyl (24-27) $\alpha$ substituted styrenes were all found to be well tolerated. Moreover, the gram-scale preparation of fluorosulfide $18(1.35 \mathrm{~g}, 80 \%)$ further underscored the practicality of this protocol. Alkenes substituted by a naphthalene (28 and 29), alkene (30), alkyne (31), heterocycle (32-35) or estrone derivative (36) also underwent the desired transformations. This protocol was also readily transferred to the preparation of the analogous chlorosulfide (37) and bromosulfide (38). Furthermore, a variety of thiophenols bearing electron-donating or electronwithdrawing groups all reacted to afford the desired fluorosulfides in moderate to good yields $(\mathbf{3 9 - 4 6 , 3 8 \% -}$ 87\%). Encouragingly, cyclohexyl- (47), benzyl- (48), and heterocycle-containing (49-52) thiols were all competent thiolating agents. Note that the applied cell potential was readjusted to $2.8 \mathrm{~V}$ when the electro- 
deficient 5-mercapto-1-methyltetrazole (51) and 2-mercapto-5-methyl-1,3,4-thiadiazole (52) were employed as the thiolating agents.

Table 2. Substrate Scope of the Electrochemical Fluorosulfenylation of Alkenes.

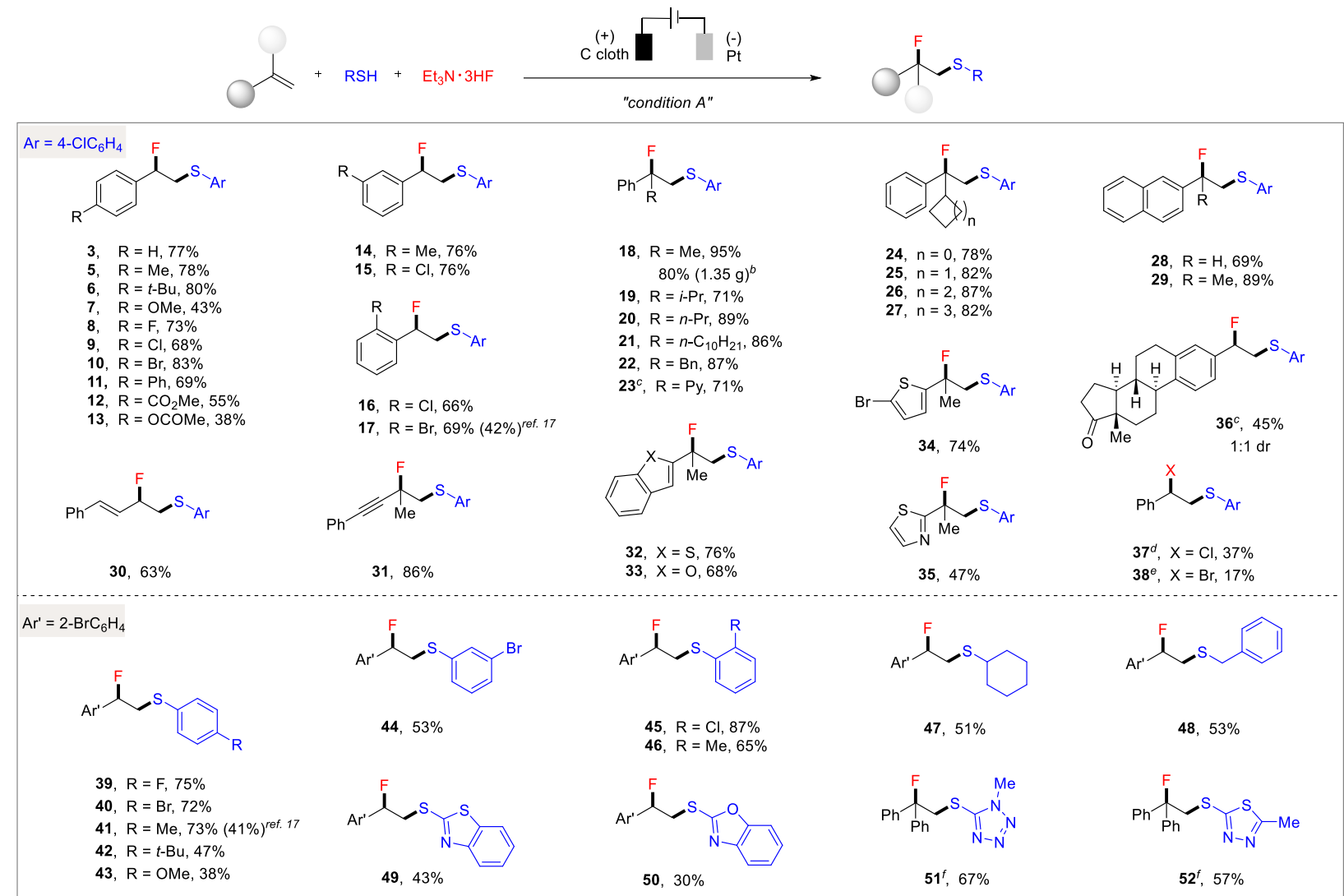

a "Condition A": undivided cell, carbon cloth anode, Pt cathode, alkene $(0.45 \mathrm{mmol})$, thiophenol $(0.3 \mathrm{mmol}), \mathrm{Et} 3 \mathrm{~N} \cdot 3 \mathrm{HF}(0.5 \mathrm{~mL})$, $\mathrm{MeCN}(10 \mathrm{~mL})$ at $40{ }^{\circ} \mathrm{C}, \mathrm{E}_{\text {cell }}=1.8 \mathrm{~V}$ for $6 \mathrm{~h}$, unless otherwise noted; yields of purified products; ${ }^{b}$ gram-scale reaction, $60 \mathrm{~h} ;{ }^{c} 20$ $\mathrm{mA}, 75 \mathrm{~min} ;{ }^{d} \mathrm{Et} 3 \mathrm{~N} \cdot \mathrm{HCl}$ (5 equiv.) used instead; ${ }^{e} \mathrm{Bu} 4 \mathrm{NBr}$ (3 equiv.) used instead; ${ }^{f} 2.8 \mathrm{~V}, 4 \mathrm{~h}$.

Compared with the existing methods, this electrochemical fluorosulfenyaltion of alkenes exhibited several advantages. First, thiols were directly used to mitigate the tedious preparation of the highly reactive and toxic electrophilic thiolating agents as shown in Scheme 1B. ${ }^{11-18}$ Therefore, previously challenging alkyl and heterocycle substituted fluorosulfides could be readily obtained (Table 2). With respect to alkenes, literature protocols were typically restricted to electron-rich alkyl substituted ones. To the best of our knowledge, only few ortho-substituted styrenes were reported by $\mathrm{Xu}$ and co-workers in the fluorosulfenylation reaction using 
$\mathrm{N}$-thiosuccinimides in moderate yields (17 and 41). ${ }^{17}$ In contrast, our method not only provided much higher yields of the same products but also tolerated a very broad scope of alkenes including styrenes, alkenyl, alkynyl, and heterocycle substituted alkenes (Table 2). Therefore, this electrochemical fluorosulfenyaltion should serve as a very general approach to fluorosulfides and is complementary to the existing methods.

Table 3. Substrate scope of the Electrochemical Fluorosulfoxidation of Alkenes.

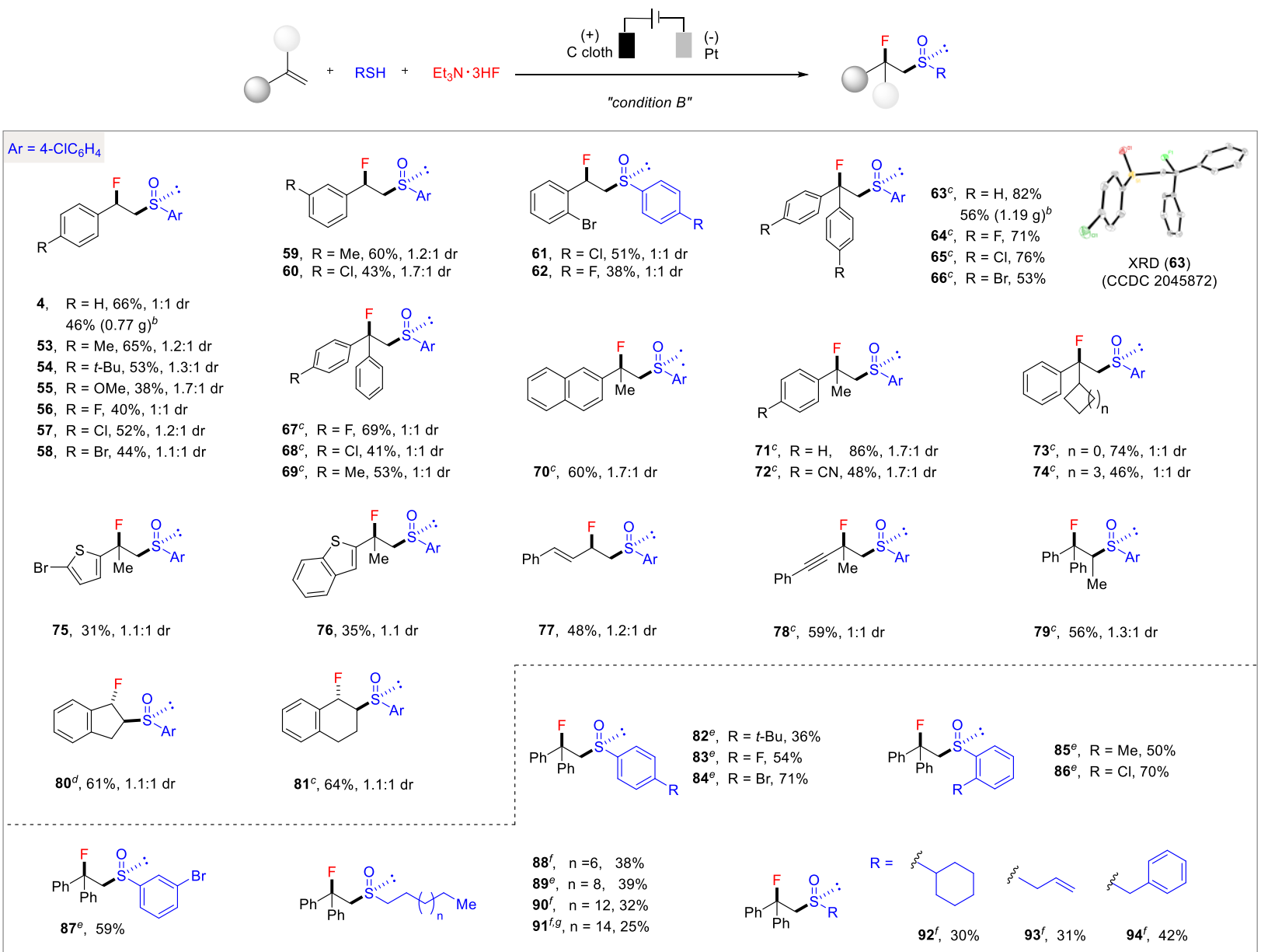

$a$ "Condition B": undivided cell, carbon cloth anode, Pt cathode, alkene $(0.51 \mathrm{mmol})$, thiophenol $(0.3 \mathrm{mmol}), \mathrm{Et} \mathrm{t}_{3} \mathrm{~N} \cdot 3 \mathrm{HF}(1 \mathrm{~mL})$, $\mathrm{CCl}_{4}$ (1 equiv.), $\mathrm{MeCN}(10 \mathrm{~mL})$ at $40{ }^{\circ} \mathrm{C}, \mathrm{CCE}$ at $20 \mathrm{~mA}$ for $4 \mathrm{~h}$, unless otherwise noted; yields of purified products; ${ }^{b}$ gram-scale reaction, $\mathrm{CCE}$ at $160 \mathrm{~mA}$ for $6 \mathrm{~h} ;{ }^{c} 3.0$ equiv. of $\mathrm{CH}_{3} \mathrm{COOH}$ were added; ${ }^{d} 3.5 \mathrm{~h} ;{ }^{e} 2.8 \mathrm{~V} ;{ }^{f} \mathrm{CCE}$ at $15 \mathrm{~mA}$ for $5 \mathrm{~h} ;{ }^{g} 55^{\circ} \mathrm{C}$.

We further applied this electrochemical difunctionalization to the facile preparation of synthetically challenging vicinal fluorosulfoxides directly from alkenes (Table 3). The target fluorosulfoxides were obtained 
as a pair of diastereoisomers since two stereogenic centers were generated. This reaction again was found to tolerate a diverse array of substrates, including substituted styrenes (53-62) and 1,1-diaryl alkenes (63-69). Our method was also well suited for the gram-scale preparation of the vicinal fluorosulfoxides $4(0.77 \mathrm{~g}, 46 \%$ yield) and 63 (1.19 g, 56\% yield). The structure of fluorosulfoxide $\mathbf{6 3}$ was unambiguously confirmed by X-ray diffraction analysis, which featured a profound sulfur-fluorine gauche effect $\left(\phi_{\mathrm{FCCS}(\mathrm{O})}=50.6^{\circ}\right)$. Furthermore, 1,1-disubstituted aryl ethylenes containing a methyl (70 and 71), cyano (72), cycloalkyl (73 and 74), heterocycle (75 and 76) group reacted to yield the desired fluorosulfoxides readily. Conjugated diene (77), enyne (78) and trisubstituted alkene (79) were also well tolerated. The vicinal fluorosulfoxidation of cyclic alkenes such as indene (80) and 1,2-dihydronaphthalene (81) afforded exclusively trans-difunctionalization products. With respect to the thiolating agents, a multitude of thiophenols (82-87) and alkyl (88-91), cyclohexyl (92), allyl (93), and benzyl (94) mercaptans were all able to provide various vicinal fluorosulfoxides in moderate to good yields $(25 \%-71 \%)$. The relatively low yields of fluorosulfoxidation with aliphatic mercaptans was consistent with the observation of appreciate amounts of alkyl disulfides even after electrolysis.

\section{Mechanistic studies}

To gain some insights into the reaction mechanism, several mechanistic experiments were then conducted. Replacement of the 4-chlorothiolphenol by its disulfide derivative (96) under standard conditions led to the desired fluorosulfide $(3,67 \%)$ and fluorosulfoxide $(63,51 \%)$ products (Scheme 2A). Consistent with this result, disulfide species were constantly observed during electrolysis, suggesting that the in-situ-generated disulfide might be a viable intermediate. The involvement of radical intermediates was substantiated by a radical rearrangement experiment (Scheme 2B). ${ }^{45}$ Additionally, the stereospecific trans-fluorosulfenylation of indene (100) and 1,2-dihydronaphthalene (102) indicated that the reaction mechanism proceeded through an episulfonium ion intermediate (Scheme 2C). Interestingly, both the (Z)- and (E)-stilbenes (104) were transformed to fluorosulfide (105) with the same stereochemistry (Scheme 2D). Monitoring the reaction revealed that a facile $\mathrm{Z} \rightarrow \mathrm{E}$ isomerization of $(\mathrm{Z})$-stilbene ${ }^{46}$ occurred before the anticipated fluorosulfenylation, 
which was likely a thiyl-radical-mediated process. ${ }^{47}$ The oxygen atoms in the sulfoxide product likely originated from the adventitious $\mathrm{H}_{2} \mathrm{O}$ in the reaction mixture ${ }^{48}$ rather than $\mathrm{O}_{2}$, as a similar yield of fluorosulfoxide (63) was obtained under rigorously oxygen-free conditions. This was further substantiated by the $\mathrm{O}^{18}$ isotope labelling experiments, which showed that the degree of $\mathrm{O}^{18}$ incorporation in the fluorosulfoxide (63) was roughly proportional to the amount of $\mathrm{H}_{2} \mathrm{O}^{18}$ added (Scheme 2E). ${ }^{49}$

Scheme 2. Mechanistic Experiments
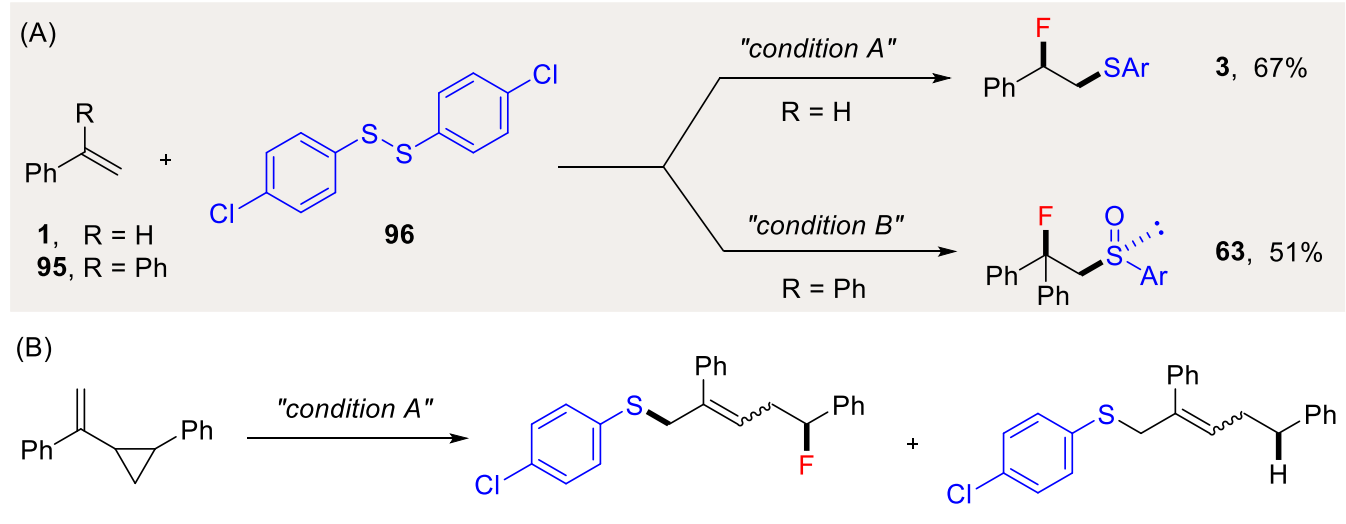

97

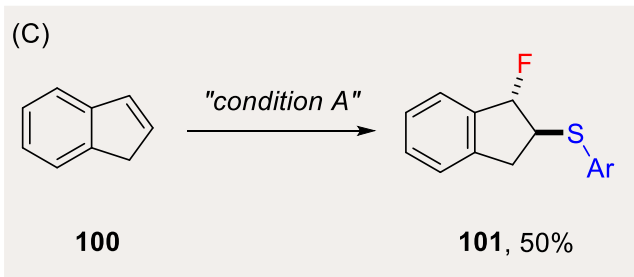

$98,15 \%$

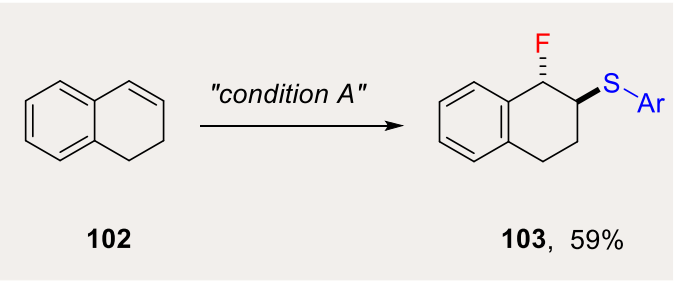

(D)

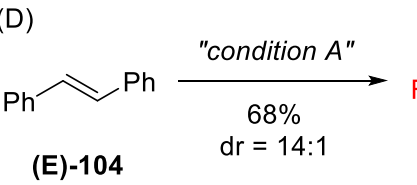<smiles>FC(c1ccccc1)C([AlH2])SC1CCCCC1</smiles>

105
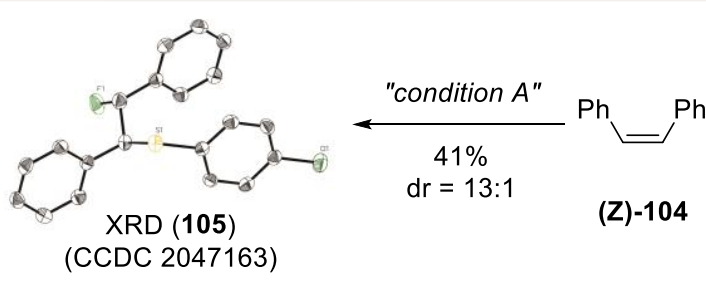

(E)<smiles>C=C(c1ccccc1)c1ccccc1</smiles>
$\frac{\mathrm{H}_{2} \mathrm{O}^{18} \text { (x equiv.) }}{\text { "condition } B "}$

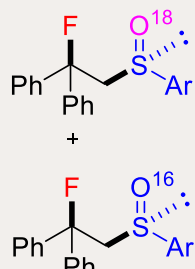

$63-0^{18}$

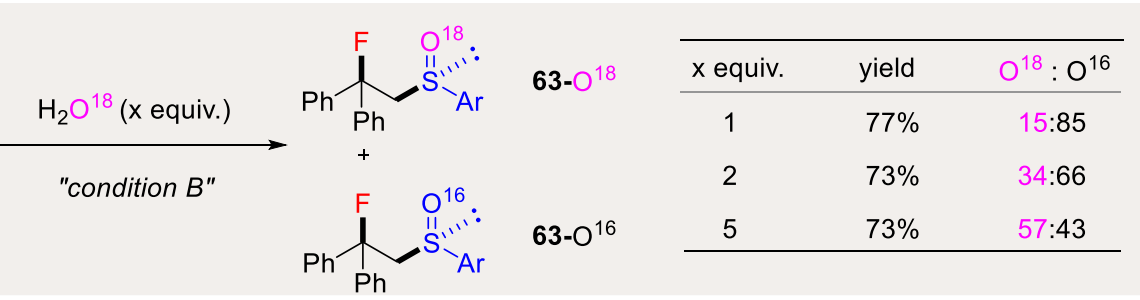


The highly selective fluorosufenylation and fluorosulfoxidation reactions well demonstrated the unique ability of the electrosynthesis to control the reactivity via "dialed-in" potentials. Cyclic voltammetry studies further supported that a judicious choice of an applied potential $\left(\mathrm{E}_{\text {cell }}=1.8 \mathrm{~V}, \mathrm{E}_{\text {anode }}=0.99-1.19 \mathrm{~V}\right.$ vs. $\mathrm{Ag} / \mathrm{AgCl}$ during the electrolysis) was the key to achieving selective fluorosulfenylation without overoxidation (Figure 1, left). Additionally, sampling experiments of fluorosulfoxidation (62) showed that the first hour of electrolysis only led to the accumulation of fluorosulfide (39, Figure 1, right). Further oxidation to fluorosulfoxide (62) was observed thereafter along with the increase in the anodic potential $\left(\mathrm{CCE}\right.$ at $20 \mathrm{~mA}, \mathrm{E}_{\text {anode }}=1.10-1.95 \mathrm{~V}$ vs. $\mathrm{Ag} / \mathrm{AgCl}$ during the electrolysis).
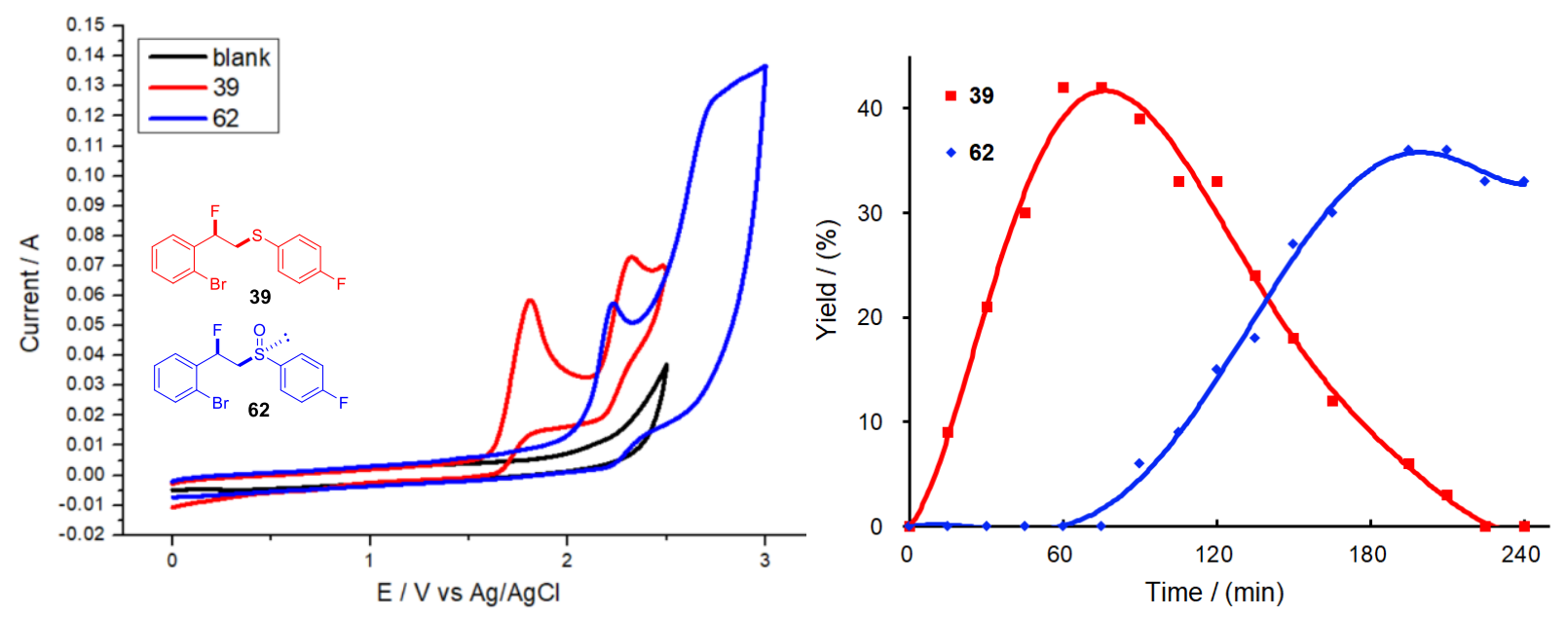

Figure 1 | Left: Cyclic Voltammograms of Fluorosulfide (39) and Fluorosulfoxide (62). Right: Sampling Experiments of Fluorosulfoxidation (62, CCE $=20 \mathrm{~mA}$, condition B). Refer Supporting Information for details.

A proposed mechanism is shown in Scheme 3. Thiophenol (A) first underwent anodic oxidation to form a thiyl radical (B), which readily dimerized to disulfide $(\mathbf{C}) .^{50,51}$ This disulfide $(\mathbf{C})$ was further oxidized anodically $^{52}$ to a thiyl radical (B) for subsequent addition to the alkene ${ }^{53}$ An alternative route to this thiyl radical via cathode reduction of disulfide $(\mathbf{C})$ was possible ${ }^{54}$ but not requisite in line with the success of this reaction even in a divided cell (refer Supporting Information for details). An episulfonium ion (E) could then be anticipated via an additional oxidation event (path a). However, an alternative pathway for forming this 
episulfonium ion from the reaction between the alkene and arylbis(arylthio)sulfonium ion (F) was also possible (path b). ${ }^{55}$ At this stage, nucleophilic attack of the fluoride to the episulfonium ion formed a corresponding fluorosulfide $(\mathbf{G}) .{ }^{56}$ The oxidation state of sulfur can be further fine-tuned by applying a higher cell potential to generate fluorosulfoxide $(\mathbf{H})$. Though the exact roles of $\mathrm{CCl}_{4}$ in this electrochemical oxidation of fluorosulfide to fluorosulfoxide still need to investigate in detail, the reductive generated chlorospecies $\left(\mathrm{Cl}^{-}\right.$ or $\mathrm{Cl} \bullet$ ) from $\mathrm{CCl}_{4}$ was proposed to facilitate this oxidation process. ${ }^{57-59}$ Further attempts to access the fluorosulfone (I) with increases of the applied potential $\left(\mathrm{E}_{\text {cell }}=2.8-3.8 \mathrm{~V}\right)$, however, only led to the decomposition of the starting material. ${ }^{60}$

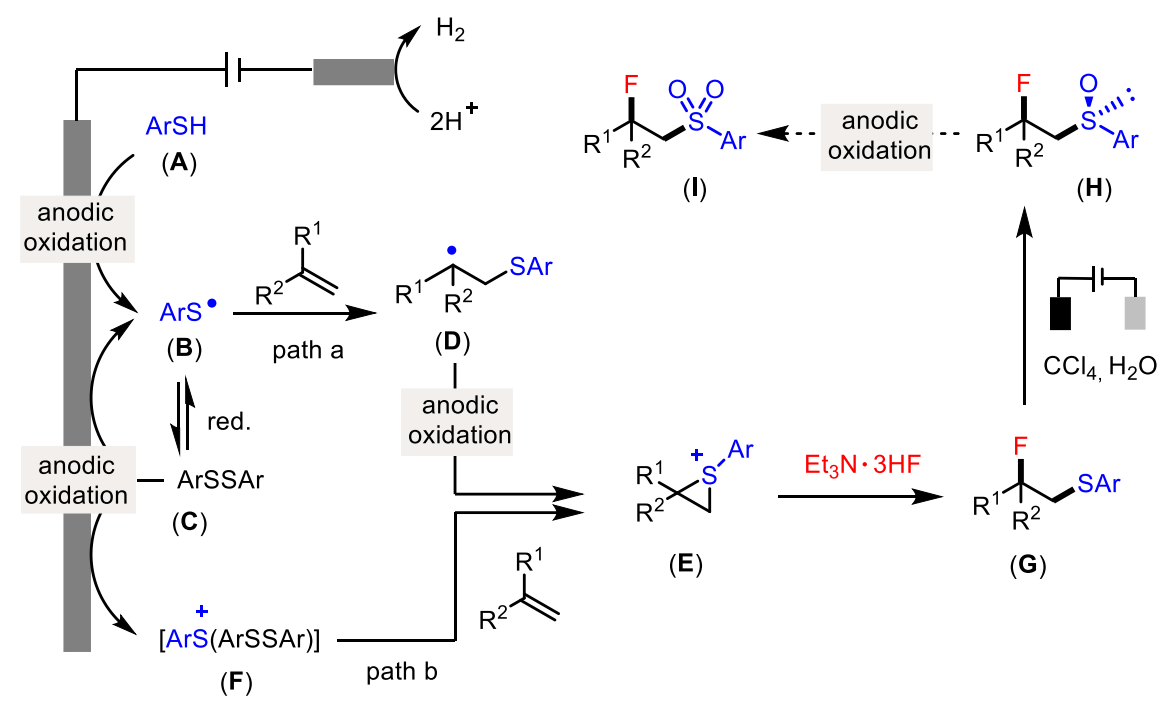

Scheme 3 | Proposed Mechanism of the Electrochemical Fluorosufenylation and Fluorosulfoxidation

\section{Conclusion}

In conclusion, we developed a highly selective, applied-potential-controlled process for the vicinal fluorosulfenylation and fluorosulfoxidation of alkenes. The protocol allowed the facile preparation of a diverse array of fluorosulfides and fluorosulfoxides that are otherwise challenging to obtain. Mechanistic investigations revealed that the judicious choice of an applied potential is the key to achieving high selectivity. Such a unique feature of electrosynthesis to control the reactivity via "dialed-in" potentials could serve as a 
conceptional inspiration for other new reaction designs. We speculated that this protocol will find broad applications for the synthesis of sulfur- and fluorine-containing molecules in the life science and materials science.

\section{Supporting Information}

Supplemental Information is available and includes description of reaction setups, synthesis procedures, compounds characterization methods and data, spectra, cyclic voltammograms, and crystallographic information (CIF) files.

\section{Conflict of Interest}

The authors declare no competing interests

\section{Funding Information}

Financial support from the National Natural Science Foundation of China (No. 21901041 and No. 21772023) State Key Laboratory of Physical Chemistry of Solid Surfaces, Xiamen University (No. 202008), and Fuzhou University (No. 510841) is gratefully acknowledged.

\section{References}

1. McDonald, R. I., Liu, G. and Stahl, S. S. Palladium(II)-Catalyzed Alkene Functionalization via Nucleopalladation: Stereochemical Pathways and Enantioselective Catalytic Applications. Chem. Rev., 2011, 111, 2981-3019.

2. Merino, E. and Nevado, C. Addition of $\mathrm{CF}_{3}$ across unsaturated moieties: a powerful functionalization tool. Chem. Soc. Rev., 2014, 43, 6598-6608.

3. Yin, G., Mu, X. and Liu, G. Palladium(II)-Catalyzed Oxidative Difunctionalization of Alkenes: Bond Forming at a High-Valent Palladium Center. Acc. Chem. Res., 2016, 49, 2413-2423. 
4. Kaiser, D., Klose, I., Oost, R., Neuhaus, J. and Maulide, N. Bond-Forming and -Breaking Reactions at Sulfur(IV): Sulfoxides, Sulfonium Salts, Sulfur Ylides, and Sulfinate Salts. Chem. Rev., 2019, 119, 8701-8780.

5. Lou, J., Wang, Q., Wu, P., Wang, H., Zhou, Y.-G. and Yu, Z. Transition-metal mediated carbon-sulfur bond activation and transformations: an update. Chem. Soc. Rev., 2020, 49, 4307-4359.

6. Haufe, G. and Leroux, F. R. Fluorine in Life Sciences: Pharmaceuticals, Medicinal Diagnostics, and Agrochemicals; Academic Press, 2019.

7. Aufiero, M. and Gilmour, R. Informing Molecular Design by Stereoelectronic Theory: The Fluorine Gauche Effect in Catalysis. Acc. Chem. Res., 2018, 51, 1701-1710.

8. Laudadio, G., Straathof, N. J. W., Lanting, M. D., Knoops, B., Hessel, V. and Noël, T. An environmentally benign and selective electrochemical oxidation of sulfides and thiols in a continuous-flow microreactor. Green Chem., 2017, 19, 4061-4066.

9. Laudadio, G., de Smet, W., Struik, L., Cao, Y. and Noël, T. Design and application of a modular and scalable electrochemical flow microreactor. J. Flow Chem., 2018, 8, 157-165.

10. Silva, F., Baker, A., Stansall, J., Michalska, W., Yusubov, M. S., Graz, M., Saunders, R., Evans, G. J. S. and Wirth, T. Selective Oxidation of Sulfides in Flow Chemistry. Eur. J. Org. Chem., 2018, 18, $2134-2137$.

11. Purrington, S. T. and Correa, I. D. The preparation of .beta.-fluoro thioethers. J. Org. Chem., 1986, 51, 1080-1083.

12. Benati, L., Montevecchi, P. C. and Spagnolo, P. Boron trifluoride-promoted reaction of 4'nitrobenzenesulphenanilide and its N-methyl derivative with alkynes. J. Chem. Soc., Chem. Commun., 1987, 1050-1052.

13. Haufe, G., Alvernhe, G., Anker, D., Laurent, A. and Saluzzo, C. Formal addition of methanesulfenyl fluoride to unsaturated substrates. Tetrahedron Lett., 1988, 29, 2311-2314. 
14. Benati, L., Montevecchi, P. C. and Spagnolo, P. Boron trifluoride-promoted reaction of 4'nitrobenzenesulphenanilide with alkynes. Formal addition of benzenesulphenyl fluoride to carbon-carbon triple bonds. J. Chem. Soc., Perkin Trans. 1, 1990, 1691-1695.

15. Saluzzo, C., Alvernhe, G., Anker, D. and Haufe, G. Synthesis of $\beta$-fluoroalkyl phenyl (or methyl) thioethers by sulfur-assisted halogen exchange with triethylamine tris-hydrofluoride. J. Fluorine Chem., 1990, 47, 467-479.

16. Haufe, G., Alvernhe, G., Anker, D., Laurent, A. and Saluzzo, C. Synthesis of fluoroalkyl methyl thioethers by formal addition of methanesulfenyl fluoride to alkenes. J. Org. Chem., 1992, 57, 714-719.

17. Liu, S., Zeng, X. and Xu, B. Practical fluorothiolation and difluorothiolation of alkenes using pyridine-HF and N-thiosuccinimides. Org. Chem. Front., 2020, 7, 119-125.

18. Shunsuke, F., Kouichi, M., Seiji, S. and Jun-ichi, Y. Thiofluorination of Carbon-Carbon Multiple Bonds Using Electrochemically Generated ArS(ArSSAr) ${ }^{+} \mathrm{BF}_{4}^{-}$. Chem. Lett., 2009, 38, 1186-1187.

19. Matviitsuk, A., Panger, J. L. and Denmark, S. E. Catalytic, Enantioselective Sulfenofunctionalization of Alkenes: Development and Recent Advances. Angew. Chem. Int. Ed., 2020, 59, 19796-19819.

20. Yuan, Z., Wang, H.-Y., Mu, X., Chen, P., Guo, Y.-L. and Liu, G. Highly Selective Pd-Catalyzed Intermolecular Fluorosulfonylation of Styrenes. J. Am. Chem. Soc., 2015, 137, 2468-2471.

21. Neufeldt, S. R. and Sanford, M. S. Controlling Site Selectivity in Palladium-Catalyzed C-H Bond Functionalization. Acc. Chem. Res., 2012, 45, 936-946.

22. Powers, D. C. and Ritter, T. Bimetallic Redox Synergy in Oxidative Palladium Catalysis. Acc. Chem. Res., 2012, 45, 840-850.

23. Maitro, G., Prestat, G., Madec, D. and Poli, G. An escapade in the world of sulfenate anions: generation, reactivity and applications in domino processes. Tetrahedron: Asymmetry, 2010, 21, 1075-1084. 
24. Yan, M., Kawamata, Y. and Baran, P. S. Synthetic Organic Electrochemical Methods Since 2000: On the Verge of a Renaissance. Chem. Rev., 2017, 117, 13230-13319.

25. Moeller, K. D. Using Physical Organic Chemistry To Shape the Course of Electrochemical Reactions. Chem. Rev., 2018, 118, 4817-4833.

26. Waldvogel, S. R., Lips, S., Selt, M., Riehl, B. and Kampf, C. J. Electrochemical Arylation Reaction. Chem. Rev., 2018, 118, 6706-6765.

27. Yuan, Y. and Lei, A. Is electrosynthesis always green and advantageous compared to traditional methods? Nat. Commun., 2020, 11, 802 .

28. Meyer, T. H., Choi, I., Tian, C. and Ackermann, L. Powering the Future: How Can Electrochemistry Make a Difference in Organic Synthesis? Chem, 2020, 6, 2484-2496.

29. Francke, R. and Little, R. D. Redox catalysis in organic electrosynthesis: basic principles and recent developments. Chem. Soc. Rev., 2014, 43, 2492-2521.

30. Peters, B. K., Rodriguez, K. X., Reisberg, S. H., Beil, S. B., Hickey, D. P., Kawamata, Y., Collins, M., Starr, J., Chen, L., Udyavara, S., Klunder, K., Gorey, T. J., Anderson, S. L., Neurock, M., Minteer, S. D. and Baran, P. S. Scalable and safe synthetic organic electroreduction inspired by Li-ion battery chemistry. Science, 2019, 363, 838-845.

31. Shen, T. and Lambert, T. H. Electrophotocatalytic diamination of vicinal C-H bonds. Science, 2021, 371, $620-626$.

32. Song, L., Fu, N., Ernst, B. G., Lee, W. H., Frederick, M. O., DiStasio, R. A. and Lin, S. Dual electrocatalysis enables enantioselective hydrocyanation of conjugated alkenes. Nat. Chem., 2020, 12, 747-754.

33. Song, C., Liu, K., Dong, X., Chiang, C.-W. and Lei, A. Recent Advances in Electrochemical Oxidative Cross-Coupling for the Construction of C-S Bonds. Synlett, 2019, 30, 1149-1163. 
34. Wang, P., Tang, S., Huang, P. and Lei, A. Electrocatalytic Oxidant-Free Dehydrogenative C-H/S-H Cross-Coupling. Angew. Chem. Int. Ed., 2017, 56, 3009-3013.

35. Fuchigami, T. and Inagi, S. Recent Advances in Electrochemical Systems for Selective Fluorination of Organic Compounds. Acc. Chem. Res., 2020, 53, 322-334.

36. Xiong, P., Long, H. and Xu, H.-C. Electrochemical Fluoroalkynylation of Aryl Alkenes with Fluoride Ions and Alkynyltrifluoroborate Salts. Asian J. Org. Chem., 2019, 8, 658-660.

37. Doobary, S., Sedikides, A. T., Caldora, H. P., Poole, D. L. and Lennox, A. J. J. Electrochemical Vicinal Difluorination of Alkenes: Scalable and Amenable to Electron-Rich Substrates. Angew. Chem. Int. Ed., 2020, $59,1155-1160$.

38. Peng, P., Yan, X., Zhang, K., Liu, Z., Zeng, L., Chen, Y., Zhang, H. and Lei, A. Electrochemical C-C bond cleavage of cyclopropanes towards the synthesis of 1,3-difunctionalized molecules. Nat. Commun., 2021, 12,3075 .

39. Laudadio, G., Bartolomeu, A. d. A., Verwijlen, L. M. H. M., Cao, Y., de Oliveira, K. T. and Noël, T. Sulfonyl Fluoride Synthesis through Electrochemical Oxidative Coupling of Thiols and Potassium Fluoride. $J$. Am. Chem. Soc., 2019, 141, 11832-11836.

40. Cao, Y., Adriaenssens, B., de A. Bartolomeu, A., Laudadio, G., de Oliveira, K. T. and Noël, T. Accelerating sulfonyl fluoride synthesis through electrochemical oxidative coupling of thiols and potassium fluoride in flow. J. Flow Chem., 2020, 10, 191-197.

41. Siu, J. C., Fu, N. and Lin, S. Catalyzing Electrosynthesis: A Homogeneous Electrocatalytic Approach to Reaction Discovery. Acc. Chem. Res., 2020, 53, 547-560.

42 Haufe, G., in Fluorination, eds. Hu, J. and Umemoto, T., Springer Singapore, Singapore, 2019, pp. 144. 
43. Zhou, Z., Yuan, Y., Cao, Y., Qiao, J., Yao, A., Zhao, J., Zuo, W., Chen, W. and Lei, A. Synergy of Anodic Oxidation and Cathodic Reduction Leads to Electrochemical $\mathrm{C}-\mathrm{H}$ Halogenation. Chin. J. Chem . 2019, 37, 611-615.

44. Yuan, Y., Yao, A., Zheng, Y., Gao, M., Zhou, Z., Qiao, J., Hu, J., Ye, B., Zhao, J., Wen, H. and Lei, A. Electrochemical Oxidative Clean Halogenation Using HX/NaX with Hydrogen Evolution. iScience, 2019, 12, 293-303.

45. Groendyke, B. J., AbuSalim, D. I. and Cook, S. P. Iron-Catalyzed, Fluoroamide-Directed C-H Fluorination. J. Am. Chem. Soc., 2016, 138, 12771-12774.

46. Waldeck, D. H. Photoisomerization dynamics of stilbenes. Chem. Rev., 1991, 91, 415-436.

47. Dénès, F., Pichowicz, M., Povie, G. and Renaud, P. Thiyl Radicals in Organic Synthesis. Chem. Rev., 2014, 114, 2587-2693.

48. Liu, S., Chen, B., Yang, Y., Yang, Y., Chen, Q., Zeng, X. and Xu, B. Electrochemical oxidations of thioethers: Modulation of oxidation potential using a hydrogen bonding network. Electrochem. Commun., 2019, 109, 106583.

49. An appreciable amount of hydroxylsulfide with $\mathrm{H}_{2} \mathrm{O}$ acting as the nucleophile was also observed. Notably, the reaction in the absence of $\mathrm{Et}_{3} \mathrm{~N} \cdot 3 \mathrm{HF}$ only resulted in the generation of trace amount of disulfide and hydroxylsulfide, see Supporting Information for details.

50. Witt, D. Recent Developments in Disulfide Bond Formation. Synthesis, 2008, 2008, 2491-2509.

51. Huang, P., Wang, P., Tang, S., Fu, Z. and Lei, A. Electro-Oxidative S-H/S-H Cross-Coupling with Hydrogen Evolution: Facile Access to Unsymmetrical Disulfides. Angew. Chem. Int. Ed., 2018, 57, 8115-8119.

52. Lam, K. and Geiger, W. E. Anodic Oxidation of Disulfides: Detection and Reactions of Disulfide Radical Cations. J. Org. Chem., 2013, 78, 8020-8027. 
53. Hoyle, C. E. and Bowman, C. N. Thiol-Ene Click Chemistry. Angew. Chem. Int. Ed., 2010, 49, 15401573.

54. Yuan, Y., Chen, Y., Tang, S., Huang, Z. and Lei, A. Electrochemical oxidative oxysulfenylation and aminosulfenylation of alkenes with hydrogen evolution. Sci. Adv., 2018, 4, eaat5312.

55. Matsumoto, K., Suga, S. and Yoshida, J.-i. Organic reactions mediated by electrochemically generated ArS ${ }^{+}$. Org. Biomol. Chem., 2011, 9, 2586-2596.

56. Pupo, G., Ibba, F., Ascough, D. M. H., Vicini, A. C., Ricci, P., Christensen, K. E., Pfeifer, L., Morphy, J. R., Brown, J. M., Paton, R. S. and Gouverneur, V. Asymmetric nucleophilic fluorination under hydrogen bonding phase-transfer catalysis. Science, 2018, 360, 638.

57. Kowalski, P., Mitka, K., Ossowska, K. and Kolarska, Z. Oxidation of sulfides to sulfoxides. Part 1: Oxidation using halogen derivatives. Tetrahedron, 2005, 61, 1933-1953.

58. Leow, W. R., Lum, Y., Ozden, A., Wang, Y., Nam, D.-H., Chen, B., Wicks, J., Zhuang, T.-T., Li, F., Sinton, D. and Sargent, E. H. Chloride-mediated selective electrosynthesis of ethylene and propylene oxides at high current density. Science, 2020, 368, 1228-1233.

59. However, preliminary results revealed the replacement of $\mathrm{CCl}_{4}$ by $\mathrm{ClCH}_{2} \mathrm{CH}_{2} \mathrm{Cl}, \mathrm{CH}_{2} \mathrm{Cl}_{2}, \mathrm{Bu}_{4} \mathrm{NCl}$, $\mathrm{NCS}$, or $\mathrm{Et}_{3} \mathrm{~N} \cdot \mathrm{HCl}$ did not lead to the desired products. Mechanistic investigation on the roles of $\mathrm{CCl}_{4}$ is currently undergoing in our lab aiming to use a greener chemical with similar effects on this oxidation step.

60. Chemical oxidation of fluorosulfoxides to fluorosulfones were readily achieved, see Supporting Information for details. 


\title{
Table of Contents Graphic (required)
}

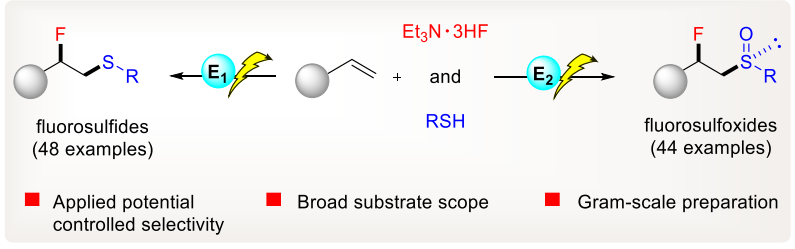

\begin{abstract}
A highly selective electrochemical process for the vicinal fluorosulfenylation and fluorosulfoxidation reactions of alkenes has been developed. The precise control of the oxidation state of sulfur moieties were enabled by the unique ability of electrosynthesis to dial in potentials on demand.
\end{abstract}

